rev.relac.int.estrateg.segur.9(1):131-154,2014

\title{
EL SOCIALISMO DEL SIGLO XXI EN AMÉRICA LATINA: CARACTERÍSTICAS, DESARROLLOS Y DESAFÍOS*
}

\author{
Álvaro Andrés Hamburger Fernández ${ }^{* *}$ \\ Ya no se trata de que una clase tome el poder social e imponga su \\ modo de apropiación de la realidad, como había ocurrido siempre, \\ sino de abolir todo modo de apropiación existente hasta nuestros \\ días y construir otro esencialmente nuevo (Ancada, 2008:52) \\ El socialismo es una opción, y existirá a partir de la voluntad y de \\ la acción que sean capaces de crear nuevas realidades (Martínez
}

Heredia, 2008:28)

\section{RESUMEN}

¿Qué es el socialismo? ¿A qué se denomina "socialismo del siglo XXI"? ¿Cuáles son las principales características de este "tipo" de socialismo? ¿Cuáles han sido sus desarrollos en América Latina y qué desafíos debe enfrentar de

* Artículo resultado de los procesos de investigación que actualmente adelanta el grupo "Emprendimiento y Gestión de Empresas de Familia", adscrito y auspiciado por el "Centro de Investigación, Innovación y Desarrollo Agroalimentario" (CIINDA), de la Universidad de La Salle.

** Doctorante en Procesos Sociales y Políticos de América Latina de la Universidad de Arte y Ciencias Sociales de Santiago de Chile (U-ARCIS). Magíster en Filosofía Latinoamericana de la Universidad Santo Tomás, Bogotá. Profesor investigador de la Universidad de La Salle. Editor de la revista Gestión \& Sociedad. Correo electrónico: ahamburguer@ unisalle.edu.co 
cara al futuro? Estos son algunos de los interrogantes que se abordan en este artículo. Este artículo tiene como objetivo responder esas preguntas para dar cuenta de la posibilidad, la viabilidad, la existencia y las condiciones que dicho socialismo debería encarnar de cara a una necesaria transformación de la realidad social, política, económica y cultural de América. El punto de partida del escrito coincide con la línea de investigación que durante varios años ha venido adelantando el argentino Atilio Borón (2000 y 2008), y que se puede sintetizar en la "inviabilidad del capitalismo como modo de producción conducente al desarrollo de América Latina" (2008:17). De ahí que el aquí denominado "socialismo de siglo XXI" emerja como el camino más expedito y directo para cambiar de rumbo y encaminar definitivamente a nuestros pueblos hacia un desarrollo integral; es decir, social, humano y económico.

Palabras clave: Socialismo, socialismo del siglo XXI, democracia, burguesía, capitalismo, neoliberalismo, América Latina.

\title{
XXI CENTURY SOCIALISM IN LATIN AMERICA: CHARACTERISTICS, DEVELOPMENTS AND CHALLENGES
}

\begin{abstract}
What is socialism? What is "socialism of the XXI century"? What are the main characteristics of this "type" of socialism? What has been its evolution in Latin America and what challenges must face in the future? These are some of the questions addressed in this article. It aims to answer these questions to account for the possibility, feasibility, existence and conditions that said socialism should stand for when facing a necessary transformation of the social, political, economic and cultural life of America. The starting point of the article coincides with the line of research that for several years has been carrying the Argentine Atilio Boron (2000 and 2008), which can be synthesized as "non-viability of capitalism as a mode of production leading to the development of Latin America" (2008:17). Hence, the so called "XXI century socialism" emerges as the most expeditious and direct way to change course and definitely lead our people towards an integral development; ie social, human and economic.
\end{abstract}

Keywords: Socialism, XXI century socialism, democracy, bourgeoisie, capitalism, neoliberalism, Latin America.

\section{SOCIALISMO DO SÉCULO XXI NA AMÉRICA LATINA: CARACTERÍSTICAS, DESENVOLVIMENTOS E DESAFIOS.}

\section{RESUMO}

O que é o socialismo? O que se denomina "socialismo do século XXI"? Quais são as principais características deste "tipo" de socialismo? Como foi seu desenvolver na América Latina e que 
desafios deve se enfrentar no futuro? Estas são algumas das questões abordadas neste trabalho. O objetivo deste artigo é o de responder a estas perguntas para explicar a possibilidade, a viabilidade, a existência e as condições nas quais o socialismo deveria encarnar em vista de uma necessária transformação da vida social, política, econômica e cultural na América. O ponto de partida do escrito coincide com a linha de pesquisa que vem sendo realizada há anos pelo argentino Atilio Boron (2000 e 2008), e que pode ser sintetizada na "inviabilidade do capitalismo como modo de produção que conduza ao desenvolvimento da América Latina" (2008:17). A partir deste aspecto é que o aqui chamado "socialismo do século XXI" emerge como o caminho mais livre e direto para mudar de rumo e encaminhar definitivamente nossos povos para um desenvolvimento integral, isto é, social, humano e econômico.

Palavras-chave: Socialismo, socialismo do século XXI, democracia, burguesia, capitalismo, neoliberalismo, América Latina.

\section{INTRODUCCIÓN}

¿Por qué hablar de socialismo hoy?, y más aún, ¿qué se entiende por "socialismo del siglo $\mathrm{XXI}^{\prime \prime}$ ? Abordar estas preguntas constituye uno de los objetivos principales de este trabajo. Para responder al primer interrogante podemos acudir a la socióloga Marta Harnecker (2011), quien afirma que "Dada la injusticia y desigualdad predominantes, hablar hoy de socialismo tiene sentido" (151). Y tiene sentido, según ella, porque a pesar de la carga negativa que ha tenido y sigue teniendo la palabra socialismo después del derrumbe de la Unión de Repúblicas Soviéticas Socialistas (URSS) y del fracaso del modelo en el resto de los países de Europa del Este ${ }^{2}$, la sociedad capitalista que se ha fortalecido desde entonces genera demasiadas contradicciones (por un lado conocimientos, ciencia y riqueza, pero por otro inequidad, pobreza y abandono) y destruye no solo al ser humano, sino también a la naturaleza ${ }^{3}$.

En esta misma línea de reflexión el ensayista cubano Fernando Martínez Heredia (2008:36-37), se pregunta: "¿qué tiene que ver hoy el socialismo con nosotros?". Contesta:

1. Para referirse al "socialismo del siglo XXI" algunos autores utilizan términos como: "democracia participativa", "nuevo socialismo" y "Nuevo Proyecto Histórico", entre otros (Véase: Dieterich, 2006).

2. La carga negativa del término socialismo, a la que alude la citada autora, se refiere a algunos aspectos que, con razón, se rechazan del modelo, tales como: "el estatismo, el capitalismo de Estado, el totalitarismo, la planificación central burocrática, el colectivismo que pretendía homogeneizar sin respetar las diferencias, el productivismo que enfatizaba en el avance de las fuerzas productivas sin tener en cuenta la necesidad de preservar la naturaleza, el dogmatismo, el ateísmo (y) la necesidad de un partido único para conducir el proceso de transición" (Harnecker, 2011:159-160).

3. En el orden de ideas que se vienen tratando en este escrito, ya existen algunos trabajos que reflexionan sobre el impacto negativo del capitalismo en la naturaleza. Michael Löwy (2011), por ejemplo, acuñó el término "Ecosocialismo" para plantear una "alternativa radical a la catástrofe ecológica capitalista". 
Opino que la única alternativa práctica, realmente existente, al capitalismo es el socialismo, y no la desaparición o el "mejoramiento" de lo que llaman globalización, que suele ser una vaga referencia al grado en que el capitalismo transnacional y de dinero parasitario ejerce su dominación en el mundo contemporáneo. Tampoco considero una alternativa suficiente el fin del neoliberalismo, palabra que hoy sirve para describir determinadas políticas y la principal forma ideológica que adopta el gran capitalismo.

Martínez Heredia (2008), hace una crítica radical al capitalismo. En efecto, denuncia que si bien es cierto que este sistema hoy por hoy ha llegado a un estado de desarrollo en el que ha desplegado todas sus capacidades con un alcance mundial, lo cierto es que su esencia sigue siendo la misma: la obtención de la ganancia y el afán de lucro, la dominación, explotación, opresión, marginalización o exclusión de la mayoría de las personas, la conversión de todo en mercancía, la depredación del medio, la guerra y todas las formas de violencia, entre otros aspectos. Concluye que el socialismo es la única propuesta capaz de eliminar el gran poder del capitalismo y, de paso, salvar a la humanidad.

Asimismo, Franz Hinkelammert (1998), citado por Tomás Moulian (2000), señala que ya el mismo Carlos Marx tenía serias sospechas sobre el capitalismo, pues lo percibía como una forma de creación de riqueza que amenaza a la vida entera, dado que no solo interviene y destruye la naturaleza, sino que deshumaniza a las personas al obligarlas a vender su fuerza de trabajo (única propiedad que poseen) de tal suerte que siendo formalmente libres las hace materialmente esclavas.

Por otra parte, y en cuanto al segundo interrogante -referido al "socialismo del siglo XXI"-, la mencionada socióloga, Marta Harnecker, señala que

"el término fue acuñado por Hugo Chávez para diferenciarlo de los errores y desviaciones del Ilamado "socialismo real" del siglo XX en la Unión Soviética y los países del Este europeo. La lección principal del proyecto chavista es la necesidad e importancia de combinar el socialismo con la democracia, no una democracia liberal, sino una democracia participativa y directa" (Harnecker, 2011:53).

Fernández y Alegre (2008) coinciden con Harnecker en que la expresión "socialismo del siglo XXI" se ha utilizado más que nada en relación con el proceso que se ha venido dando en los últimos años en la República Bolivariana de Venezuela. Sostienen estos autores que "En Venezuela se están demostrando algunas cosas que desmienten la mayor parte de los lugares comunes desde los que se pensaron en el siglo XX las relaciones entre socialismo y democracia" ${ }^{4 \prime}$ (88).

4. Un desarrollo más pormenorizado de estas ideas es posible hallarlo en: Fernández Liria, Carlos y Alegre Zahonero, Luis (2006). Comprender Venezuela, pensar la democracia. El colapso moral de los intelectuales occidentales. En esta 
De todas formas, el socialismo del siglo XXI, tanto desde el punto de vista teórico como desde el punto de vista práctico, desborda la experiencia venezolana y plasma la existencia de una tendencia que cada día toma mayor fuerza en toda Latinoamérica. Esta tendencia busca dar respuestas al grave problema de subdesarrollo en que vive sumida la región debido, fundamentalmente, a los desequilibrios sociales, la injusticia y la inequidad que ha sembrado el modo de producción y las prácticas políticas instauradas, desarrolladas y perpetuadas por el capitalismo. Precisamente, el cometido de este artículo gira en torno a la caracterización, evolución y análisis de la viabilidad de dicha tendencia; es decir, del socialismo del siglo XXI.

\section{RAÍCES SOCIALISTAS DEL SOCIALISMO DEL SIGLO XXI}

Como es natural, el socialismo del siglo XXI se puede comprender mejor si existe claridad sobre qué es el socialismo, puesto que aquél no es una expresión distinta de éste, sino, por el contrario, su más pura manifestación en la nuevas realidades y en los nuevos desafíos de la sociedad actual, una realidad mucho más compleja que la del siglo pasado. En tal sentido, es necesario recordar que, para sus fundadores, el socialismo es el periodo de transición ${ }^{5}$, relativamente prolongado, del capitalismo al comunismo (Marx y Engels, 1974; Engels, 1965 y Lenin, 1961). En efecto, el socialismo

Es la fase caracterizada por la coexistencia en lucha de las nuevas relaciones sociales de producción (que no pueden ser concebidas de otra manera sino como relaciones de producción comunistas) y las viejas relaciones capitalistas, lucha que se expresa necesariamente en todos los sectores de la vida social y en la que las relaciones sociales comunistas van sustituyendo gradualmente a las viejas, gracias a la incesante acción revolucionaria de las clases y sectores sociales interesados en esa subversión profunda de lo existente (Ancada, 2008:52).

De acuerdo con Ancada (2008:55-58), para poder comprender a cabalidad el socialismo es necesario tener en cuenta los siguientes elementos, presentes en las concepciones de Marx, Engels y Lenin:

obra los autores sostienen que Venezuela es el único caso en el que un proyecto socialista que toma el camino del derecho constitucional ha resistido todas las presiones y amenazas y, además, está demostrando en los hechos que existe compatibilidad entre socialismo y democracia.

5. Jorge Luis Ancada retoma esta idea que Marx y Engels (1979a), desarrollaron en el primer capítulo del Manifiesto del Partido Comunista. Según Ancada, la mutación del capitalismo al comunismo hace necesaria una transformación radical que implica la existencia de un período o fase de transición relativamente prolongado. Marx denominó "socialismo" a ese período de transición. 
- Finalmente la superación de las relaciones capitalistas de producción no será el resultado automático de las transformaciones acaecidas en la economía, sino que será resultado de la lucha de clases manifestada en todas las esferas de la vida social.

- El desarrollo de las fuerzas productivas incide en la transformación de las relaciones sociales de producción; sin embargo, las fuerzas productivas no pueden ser reducidas a tecnología, maquinaria e industria. Por el contrario, dichas fuerzas se relacionan fundamentalmente con las capacidades productivas del ser humano (lo cual implica: características del conocimiento y de su producción, formas de organización de la producción -tanto de la material como de la espiritual-, relaciones de propiedad habidas y formas de existencia del trabajo, entre otros aspectos) ${ }^{6}$.

- En el socialismo no existen, propiamente hablando, relaciones "socialistas" de producción y, mucho menos, "modos de producción socialista", pues como ya se dijo, el socialismo es una etapa prolongada de cambios y transformaciones en la que, por medio de la lucha, se superan las viejas relaciones sociales de producción capitalistas y se imponen gradualmente las nuevas relaciones de tipo comunista.

- La esencia del modo de producción capitalista se halla en la compra-venta de la fuerza de trabajo. Mientras existan quienes estén dispuestos a vender su fuerza de trabajo y existan quienes puedan comprarla, el núcleo mismo del capitalismo permanecerá. Aun cuando el Estado se convierta en propietario universal de los medios de producción y en comprador de la fuerza de trabajo, ello no cambiaría el estado de cosas; en otras palabras, la estatalización de la propiedad no implica que ésta se socialice.

- La estatalización de la propiedad, además, no elimina a la clase obrera; por el contrario, la perpetua, lo cual va en contra de los objetivos originales del socialismo, pues este busca suprimir todas las clases, incluida la clase proletaria. La eliminación de las clases sólo será posible cuando se dé una socialización real y efectiva de la propiedad que lleve a los sectores productivos de la sociedad a establecer otro tipo de relación con los medios de producción.

- El socialismo busca la superación gradual e incesante de la enajenación que producen las relaciones monetario-mercantiles, el trabajo asalariado y la división social del trabajo.

- El socialismo no puede ser concebido como una sociedad carente de conflictos y luchas pues, dadas las condiciones imperantes en el proceso productivo, existen clases y donde existen

6. En el acápite "Desarrollo de las fuerzas productivas como premisa material del comunismo", del primer capítulo de La ideología alemana, Marx y Engels (1979b) despliegan con mayor profundidad esta idea. 
clases se da la lucha de clases. De lo que se trata es de saber aprovechar las contradicciones y conflictos para generar condiciones de relaciones sociales de producción comunistas.

- El proceso histórico hacia el comunismo tiene que ser un proceso universal. Es prácticamente imposible que un país logre la construcción del comunismo si sigue inserto en un sistema económico internacional regido por el sistema capitalista.

- Dado que el Estado es un instrumento de poder de una clase, el objetivo del socialismo, como etapa de transición, consiste en la gradual extinción del Estado.

Otro autor que intenta precisar y hacer más útil para el trabajo intelectual el concepto de socialismo, es Fernando Martínez Heredia. Para él, contrario a lo que muchos piensan, "El socialismo no surge de la evolución progresiva del capitalismo" (2008:28). El capitalismo sólo puede engendra más capitalismo, por lo tanto el socialismo debe ser capaz de crear realidades totalmente nuevas, tal como el capitalismo supo hacerlo en su momento. Según este autor ha habido dos maneras diferentes de entender el socialismo en el mundo del siglo XX (Martínez Heredia, 2008:31-35):

1. Un socialismo "que pretende cambiar totalmente el sistema de relaciones económicas mediante la racionalización de los procesos de producción y de trabajo, la eliminación del lucro, el crecimiento sostenido de las riquezas y la satisfacción creciente de las necesidades de la población" (31). Este socialismo busca alcanzar los ideales de justicia social y de armonía universal prometidos por la modernidad y que nunca se han alcanzado; presupone un gran desarrollo económico, una gran liberación de los trabajadores y una democracia muy superior a la que hasta ahora se ha logrado en el capitalismo. Pero además, este socialismo, de ser alcanzado, garantizaría completamente las libertades individuales, tendría instituciones intermedias, contrapesos, control ciudadano, extinción progresiva de los poderes y productores libres. Una sociedad con estas características no la puede garantizar el capitalismo, por lo tanto este debe ser erradicado y reemplazado por el socialismo.

2. Un socialismo que busca "conquistar en un país la liberación nacional y social derrocando al poder establecido y creando un nuevo poder, ponerle fin al régimen de explotación capitalista y sus sistema de propiedad, eliminar la opresión y abatir la miseria, y efectuar una gran distribución de las riquezas y de la justicia" (32). Este socialismo se propone lograr un auténtico respeto a la integridad y la dignidad humana y garantizar la alimentación, la salud, la educación y el empleo para todos. Busca, además, hacer respetar el derecho de las mayorías y las promesas de igualdad efectiva de las personas más allá de su ubicación social, género, raza y edad. El gran reto de este tipo de socialismo consistiría en eliminar el subdesarrollo, fundar instituciones y cultura democráticas y crear un Estado de derecho en un ambiente de relaciones económicas internacionales más justas. En este socialismo se hace necesario también, como en el primero, crear una nueva cultura, diferente y opuesta a la del capitalismo. 
Ahora bien, en la misma línea de reflexión de los autores citados, pero desde una perspectiva algo diferente, Julio César Guanche (2008:201), sostiene que "El marxismo ha analizado con profusión la necesidad de socializar la economía, y de superar el régimen de producción basado en la lógica del capital, pero no lo ha hecho del mismo modo con el problema conexo de la necesidad de socializar el poder". Y agrega:

Aunque se trate de un mismo tema -el dilema político de cómo instituir una sociedad emancipada- el tratamiento de este último problema no queda cubierto por el análisis de la socialización de la economía. La esencia del asunto no es imaginar la extinción del Estado nación, ni siquiera pensar la extinción del Estado mismo, sino medir la fortaleza de la revolución por la manera en que el poder político se va socializando".

La crítica de Guanche ${ }^{7}$ se centra en la necesidad de otorgarle autonomía al socialismo, pues en la tradición del marxismo revolucionario el socialismo jamás resulta un proceso político con horizonte propio: es, como ya se ha dicho, un medio para alcanzar un fin: el comunismo (el socialismo no ha sido definido como un "modo de producción" autónomo, sino como una especie de purgatorio: la preparación de la vida futura del comunismo ${ }^{8}$ ). Los estudios realizados por este autor, lo llevan a concluir -sobre la base de los planteamientos de André Gunder Frank ${ }^{9}$ (1970) -, que los países subdesarrollados sólo pueden superar su subdesarrollo rompiendo con el sistema capitalista; es decir, por medio de una revolución socialista. En este proceso revolucionario el socialismo debe desempeñar un papel primordial: la socialización del poder político por medio de la expansión de la democracia.

\section{CARACTERIZACIÓN DEL SOCIALISMO DEL SIGLO XXI EN AMÉRICA LATINA}

Los estudiosos del socialismo del siglo XXI, entendido como el camino más apropiado y eficaz para transformar la realidad de subdesarrollo y dependencia en el que vive sumida Latinoamérica, coinciden en que es necesario construir una "auténtica democracia" en la región y en cada uno de sus países. Esta democracia tendría que ser una democracia postneoliberal. Díaz Salazar (s.f.), citado por Monedero (2010), considera que el punto de partida debe ser

7. Para un tratamiento más profundo de este asunto, véase su ensayo "Todo lo que existe merece perecer (o una pregunta distinta sobre la democracia)", en: Cuadernos de Pensamiento Crítico RUTH Nº1,:201-243. Panamá: RUTH, Casa Editorial (Guanche, 2008).

8. Como se sabe, en la tradición marxista "el comunismo es el nombre dado al programa de la socialización del poder, al régimen del trabajo libre, al estatuto de la organización de los productores, al sistema resultante de la expropiación de los expropiadores" (Guanche, 2008:202).

9. Los estudios de Gunder Frank (1970), demostraron que el subdesarrollo era el tipo de desarrollo que podía tener Latinoamérica; que el subdesarrollo no es una etapa, sino una condición del mantenimiento de la condición de desarrollados para los países que ya conquistaron dicho estatus. En otras palabras, la causa del subdesarrollo de América Latina ha sido su integración al sistema capitalista mundial, empezando con la Conquista. 
La dignidad inviolable de todo ser humano, lo cual exige equidad. Ello conlleva construir una sociedad mundial con un reparto justo de los recursos entre todos los habitantes del planeta, desbordando de una vez por todas, el marco del Estado nación. Las declaraciones y pactos internacionales sobre los derechos humanos integrales (civiles, políticos, sociales, económicos y culturales) son el orden constituyente que debe regular la acción de los gobiernos y de las instituciones mundiales (243).

Díaz Salazar (s.f.), citado por Monedero (2010:243-245), ha resumido las propuestas que constituirían esa nueva democracia así:

- Los bienes universales (agua, aire, bosques, alimentos, semillas, etcétera) constituyen un patrimonio común de toda la humanidad y un derecho básico de todos los hombres. Por lo tanto, no pueden ser mercantilizados, privatizados y patentados, pues son de propiedad colectiva. Todos los seres humanos deben tener acceso universal a dichos bienes. Además, los servicios públicos que garantizan una vida humana de calidad (salud, educación, seguridad social, vivienda, energía doméstica, renta básica, etcétera), no pueden ser sometidos a la lógica del mercado; es decir, no deben ser privatizados.

- La democracia debe ser una "democracia radical"; es decir, una democracia expansiva que imponga la soberanía popular sobre cualquier otro tipo de poder político o económico. Este tipo de democracia garantiza el cumplimiento de los derechos humanos integrales, el pluralismo y la separación de poderes.

- $\quad$ Se debe propender por la sustentabilidad ecológica, que es la base de la reproducción de la vida y el requisito imprescindible para la solidaridad con las generaciones futuras.

- Es preciso optar por la no violencia como fundamento de la vida en comunidad. Los conflictos se deben resolver por la vía del diálogo y los medios pacíficos.

- Se deben respetar la identidad y la diversidad. No se debe aceptar la homogeneización mundial promovida por el capitalismo, pues la tolerancia y el pluralismo son imprescindibles para la construcción de una vida auténticamente colectiva. Se debe promover el diálogo entre culturas, religiones y civilizaciones.

- Es preciso alentar la subsidiaridad como fundamento de la democracia participativa, la proximidad entre los seres humanos y la descentralización del poder.

- La economía se debe poner al servicio de la persona humana, de la satisfacción de las necesidades básicas y de la primacía del factor trabajo sobre el factor capital. Antes que una economía de la acumulación y de la plusvalía se debe imponer una economía solidaria y popular. 
- En indispensable fomentar el derecho a la cultura, tanto en su producción como en su consumo. Se debe elevar el nivel cultural de los individuos y de los pueblos. En esto juegan un papel primordial la calidad y la democratización de los medios de comunicación social de masas.

- Se debe poner el énfasis en la solidaridad entendida como antropología de la ternura social y de la fraternidad. Esto implica hacer frente a la ley de la selva fortalecida por la globalización neoliberal y vigorizar un tipo de ser humano sensible ante el dolor y la injusticia ajenos.

- Es necesario crear estructuras sociales donde los ciudadanos puedan vivir realmente la libertad, la igualdad y la fraternidad.

En la misma línea de reflexión de los citados Díaz Salazar y Monedero, Marta Harnecker propone unos "rasgos del socialismo del siglo XXI" en perspectiva latinoamericana. Esos rasgos son esencialmente cinco, a saber: el hombre como ser social, el pleno desarrollo humano, una democracia participativa y protagónica, un nuevo modelo económico, y un alto grado de descentralización que permita un real protagonismo popular. Veamos a continuación, en detalle, estos aspectos (Harnecker, 2010:34-49):

1. El hombre como ser social (punto de partida). "El punto de partida del socialismo del siglo XXI es la persona humana como ser social. Nuestra concepción socialista no parte, como lo hace el capitalismo, de la persona como ser individual, de la persona aislada, separada de las demás, sino de la persona que sólo puede desarrollarse a sí misma si se desarrolla junto a otra" (35). No existe el ser humano abstracto ${ }^{10}$. Sin embargo, esta posición no niega al individuo, lo que plantea es que la naturaleza humana individual es eminentemente social, y que cuando el individuo desarrolla valores sociales (la solidaridad, por ejemplo), se desarrolla más plenamente como individuo. Hay una relación dialéctica complementaria entre el ser individual y el ser social, lo cual hace que se rechace también el colectivismo; es decir, el enfoque que suprime las diferencias de cada miembro de la sociedad en nombre del colectivo y lo "masifica".

2. El pleno desarrollo humano (punto de llegada). El socialismo del siglo XXI tiene por meta el pleno desarrollo humano ${ }^{11}$. El pleno desarrollo humano se construye con la gente (con la participación popular). Es un proceso de autoconstrucción personal y de transformación

10. “Como dice el filósofo francés Henry Lefebvre: alguien que está por encima de todo, que no es ni rico ni pobre, ni viejo ni joven, ni macho ni hembra o lo es todo a la vez" (Harnecker, 2010, p.35). Por el contrario, como dice el yugoslavo Miofrag Zecevic (1977): “Lo que existen son personas concretas, que viven y depende de otras personas, que se asocian y organizan de diferentes maneras con otras personas en comunidades y organizaciones en las cuales y por medio de las cuales realizan sus intereses, sus derechos y sus deberes".

11. Véase, por ejemplo: Michael Lebowitz (2006 y 2008). En estas obras Lebowitz critica abiertamente al sistema capitalista y le atribuye un carácter deshumanizante y antidemocrático: "El capitalismo no es un camino para el desarrollo humano; su esencia es colocar a la gente unos contra otros para después obtener ganancias. Es como 
social que se da desde la base y, por lo tanto, no es una dádiva ni una simple decisión del gobierno: requiere de un basamento democrático; de una democracia práctica, es decir protagónica y participativa.

3. Una democracia participativa y protagónica. Esta se construye de dos maneras: primero: a partir de la participación popular, y, segundo: dando el paso de la democracia representativa a la democracia delegada. Lo primero exige cuatro escenarios: a) No dar contenido social a la democracia, sino transformar la forma misma de la democracia, b) fomentar el desarrollo humano a través de la participación popular, c) Crear espacios adecuados para la participación y, d) promover la democracia y el pluralismo. Lo segundo precisa de dos aspectos: a) pasar de la participación en espacios pequeños a un sistema de delegación o vocería y, b) establecer claras diferencias con el sistema representativo burgués.

4. Un nuevo modelo económico ${ }^{12}$. Este supone cinco escenarios básicos: a) Poner a la persona humana en el centro de los sistemas productivos, b) crear un modelo que respete la naturaleza y que combata el consumismo, c) implementar el triángulo elemental del socialismo (propiedad social de los medios de producción, producción organizada por los trabajadores y satisfacción de las necesidades comunales), d) generar un nuevo concepto de eficiencia (a partir del respeto a la naturaleza y al pleno desarrollo humano, la eliminación del trabajo alienado -pues no es eficiente-, la formación para la participación y la inversión en desarrollo humano -pues es productiva-) y e) implementar una economía planificada.

5. Un alto grado de descentralización que permita un real protagonismo popular. Esto se logra si se aplican las siguientes máximas: a) no hay protagonismo popular sin descentralización, b) la descentralización es el antídoto contra el burocratismo, c) no se puede administrar todo centralmente, sólo el control social puede evitar la corrupción, d) hay que descentralizar todo lo que se puede descentralizar y, e) el Estado central no se debilita, se fortalece.

hacer caer todo al nivel más bajo" (2008, p.45). Además, sostiene que el concepto de desarrollo que se maneja en el capitalismo es reduccionista y miope, pues "lo limita a mero crecimiento económico" (2006, p.67).

12. Álvaro Hamburger (2008:.309-310), habla de "una nueva forma de hacer economía", que se caracteriza por los siguientes postulados: $1^{\circ}$ ) el ser humano está por encima del capital; el dinero es un medio, lo principal es el hombre, $2^{\circ}$ ) la mejor manera de propiciar el desarrollo de un país es propender por la calidad de vida de las personas, $3^{\circ}$ todos los habitantes de un país deben tener acceso al bienestar y a una vida digna, $4^{\circ}$ ) las empresas, como las personas, tienen alma; hay que humanizar las empresas, $5^{\circ}$ ) el capitalismo ha generado un gran desarrollo y enormes riquezas que se han quedado en manos de pocos. Es preciso redistribuir la riqueza y llevar el desarrollo a todos los habitantes del planeta, $6^{\circ}$ ) los líderes del futuro serán líderes del desarrollo a escala humana, $7^{\circ}$ ) el verdadero desarrollo se basa en la inclusión social, la protección de los niños, el cuidado de los ancianos, la lucha contra el hambre y la miseria y la protección de la mujer, $8^{\circ}$ ) si el ser humano no cambia de rumbo, difícilmente dejará a sus descendientes un planeta habitable o una sociedad en la que puedan ser felices, $9^{\circ}$ ) una empresa exitosa es aquella en la que se respetan los derechos humanos, se acatan los derechos en el trabajo, se protege el medio ambiente y se lucha contra la corrupción, $y, 10^{\circ}$ ) la responsabilidad social es una obligación moral de las empresas y los sistemas productivos. 


\section{EL DEVENIR DEL SOCIALISMO DEL SIGLO XXI EN AMÉRICA LATINA}

Como se ha afirmado en los acápites anteriores, la meta que persigue el socialismo es el pleno desarrollo humano, no el desarrollo por el desarrollo, la economía por la economía o la política por la política; todas estas realidades cobran sentido cuando se las mira a la luz de la persona humana y su circunstancia histórico-social concreta. Ello es universalmente válido, pero se hace más evidente si se habla de América Latina, pues como se sabe, el desarrollo se hace más necesario y más sentido precisamente ahí donde ha brillado por su ausencia. En efecto, una gran parte de este territorio se debate entre el subdesarrollo, la pobreza y la dependencia. Justamente en virtud de ello, y luego de una breve reflexión sobre la historia económica comparada, Atilo Borón sostiene que "quien quiera hoy hablar de desarrollo tiene que estar dispuesto a hablar de socialismo; y si no quiere hablar de socialismo, debe callar a la hora de hablar de desarrollo económico" (2008:40). Evidentemente, se refiere a que la ruta capitalista hacia el desarrollo está cerrada y que es necesario crear una nueva, dado que dentro del capitalismo no hay solución para los múltiples problemas de Latinoamérica. Borón concluye que "Si hay una solución -y si tenemos tiempo de encontrar una solución, dada la amenaza de holocausto ecológico que se cierne sobre el planeta-, habrá que buscarla fuera del capitalismo, en el campo del socialismo" (41). A partir de esta constatación este autor se propone elaborar una definición del horizonte socialista y lo hace por medio de una reflexión tripartita: los valores y principios modulares, el programa del proyecto y el sujeto histórico de ese proyecto. Veámoslo en detalle (Borón, 2008:101-135):

1. Los valores y principios modulares. Lo primero que hay que afirmar en este aspecto es la incuestionable superioridad ética del socialismo con respecto al capitalismo. En efecto, el socialismo es una forma superior de civilización, dado el predominio que en él ejercen valores como el altruismo, la solidaridad, la democracia, el respeto a la naturaleza y el aprecio de la sociodiversidad, entre oros. Luego habría que decir que el aparataje axiológico del socialismo del siglo XXI se construye sobre una afirmación y una negación: la primera se refiere a la superación de la visión economicista; mientras que la segunda se refiere a los antivalores que no se deben asumir. En cuanto a la abolición del economicismo, es claro que el valor fundamental es la persona y, en tal sentido, la economía debe estar al servicio de ella y no la persona al servicio de la economía, como ha ocurrido hasta ahora con el capitalismo. Esto implica asumir dos valores fundamentales: la solidaridad entre las personas y el respeto a la naturaleza ${ }^{13}$. En cuanto a los antivalores que no se deben asumir, Lebowitz (2006), citado por Borón (2008), sostiene que son los siguientes: el estatismo ("el socialismo del siglo XXI no es estatismo ni puede dar lugar a una sociedad estatista" -106-), el populismo

13. En este sentido, François Houtart (2007), citado por Atilo Borón (2008), identifica cuatro principios indispensables para el socialismo del siglo XXI: el primado del valor de uso sobre el valor de cambio, una nueva relación no predatoria con la naturaleza, la democratización de todas las esferas de la vida social, y el predominio de la interculturalidad. 
("el socialismo no es populismo. Un Estado que provee los recursos y las soluciones a todos los problemas de la gente no fomenta el desarrollo de las capacidades humanas... -108-), el totalitarismo ("dado que los seres humanos son diferentes y tienen diferentes necesidades y habilidades, su desarrollo por definición requiere del reconocimiento y respeto de las diferencias" -108-), la idolatría de la tecnología ("el socialismo no puede ser el culto por la tecnología sobre el pretexto que esta beneficia la economía de gran escala" -109-) y, finalmente, la resignación ante la lógica del capital ("el socialismo del siglo XXI debe estar dispuesto a luchar contra el sistema capitalista" -110-).

2. El programa del proyecto. Si bien los valores expuestos encarnan el ideal socialista y constituyen la utopía movilizadora del socialismo, lo cierto es que todo ideario debe tener asideros concretos que se hagan histórica y realmente visibles en un proyecto de transformación social. De no ser así el socialismo del siglo XXI correría el riesgo de quedar relegado al terreno de las ideas despojadas de toda resonancia práctica. Así las cosas, este proyecto debe asumir, al menos, dos grandes programas. El primero se refiere a una planificación económica que se ajuste a las necesidades concretas y particulares de América Latina (especialmente a las circunstancias de cada país en su aquí y su ahora). Nada indica que se beban imitar modelos extranjeros; por ejemplo, hoy nada justificaría un esquema centralizado de dirección y control de la vida económica y, mucho menos, su completa estatización, como en su momento ocurrió en la Unión Soviética, pues ello favorecería el predominio de la burocracia y la consolidación de sus intereses. El segundo programa, por su parte, se refiere al rompimiento del "pensamiento único" que mitifica al socialismo y lo concibe como un sistema monolítico, dogmático y estático aplicable en cualquier lugar del mundo y en cualquier época de la historia. Por el contrario, hoy se necesita un socialismo diferente, capaz de reinventarse a sí mismo, capaz de crear nuevas realidades, de hacer nuevas alianzas, de romper viejos esquemas. En efecto, "Aferrarse a un viejo modelo, aunque haya sido exitoso en el pasado, cuando se han extinguido las condiciones que lo hacían posible y razonable equivale a internarse en una ruta que culmina inexorablemente en un mayúsculo y penoso fracaso" (Borón, 2008:116). Por eso, como afirma Mariátegui: "No queremos, ciertamente, que el socialismo sea en América calco y copia. Debe ser creación heroica. Tenemos que dar vida con nuestra propia realidad, en nuestro propio lenguaje, al socialismo indoamericano. He aquí una misión digna de una generación nueva" (1969:247).

3. El sujeto histórico del proyecto. El sujeto histórico es el ser humano considerado en su condición social, no individual. En efecto, poco pueden lograr los sujetos si actúan de manera individual y aislada; se necesita del sujeto social, de grupos organizados que opongan resistencia y oposición organizada y consciente a las tendencias capitalistas. La noción de "pueblo" es la que mejor puede describir dicho sujeto. Esta noción, además, ha evolucionado con el tiempo, hoy ya no se trata sólo del proletariado (entendido en su acepción clásica), sino de una gran variedad de movimientos sociales y grupos organizados que luchan por construir una nueva sociedad: asociaciones comunales, mujeres, jóvenes, ecologistas, pacifistas, negritudes, indígenas, campesinos y defensores de los derechos 
humanos, entre otros. Lo primero que hay que entender, entonces, es que existen diversos sujetos sociales luchando por diferentes causas que expresan, en conjunto, las inmensas contradicciones generadas por la sociedad capitalista. El socialismo del siglo XXI debe propender por una construcción social y política que parta de la unidad de todos estos sujetos; de ahí surge, precisamente, su reto más importante, puesto que "los lenguajes, las culturas, las tradiciones, mentalidades e ideologías de estos componentes del campo popular son muy diversos, y que la labor de sintetizarlos en una fórmula organizativa y política coherentes es una tarea de una enorme complejidad" (Borón, 2008:129-130).

\section{PRINCIPALES DESAFÍOS DEL SOCIALISMO DEL SIGLO XXI EN AMÉRICA LATINA}

Después de todo lo planteado hasta aquí, es pertinente preguntarse con Eagleton (2006): ¿Existe un futuro para el socialismo?; aún más, ¿existe un futuro para el socialismo en América Latina? Eagleton no cree que el socialismo esté sufriendo una especie de bancarrota en el sentido de "estar carente de ideas". Piensa que "todavía existen muy buenas ideas de izquierda en todas partes, y un no menos fértil y sugerente corpus de trabajo sobre cómo podría ser una economía socialista, y hasta qué punto los mercados aún serían necesarios para cumplir con ciertas funciones" (470). No cree que el sistema capitalista sea invulnerable: aunque este sistema es monumentalmente poderoso y estable, es perfectamente capaz de detenerse abruptamente sin la ayuda de sus enemigos políticos; es decir, no hace falta el socialismo para que colapse el capitalismo, sólo hace falta el capitalismo mismo, dado que, por las contradicciones y crisis que produce, este puede cometer un "haraquiri". Si esto es así, ¿̇entonces para qué se necesita el socialismo? Se necesita, concluye Eagleton, "para derribar el sistema antes de que nos arroje a todos a la barbarie. Para resistir tanto como sea posible el fascismo, el caos y el salvajismo que seguramente surgirán de una crisis mayúscula del sistema" (471). El socialismo vine a cumplir, entonces, un papel mesiánico ${ }^{14}$.

Por su parte, Tomás Moulian (2000) cree que el "nuevo socialismo" para el siglo XXI debe enfrentar numerosos y complejos desafíos. Para empezar tiene que abandonar el error principal del "viejo socialismo": la Estadolatría o el culto al Estado"15. "Una política socialista

14. En este sentido, y recordando a Walter Benjamin y a Bertolt Brecht respectivamente, Eagleton (2006) afirma que "la revolución no es un tren fuera de control, sino la aplicación de los frenos de emergencia", y que "el capitalismo, y no el socialismo, es radical". En este sentido, el rol de las ideas socialistas es el de proteger el futuro que todavía no ha nacido.

15. Según Moulian: "El Estado no debe escribirse con mayúsculas. No es ni el origen de toda la decisión política, ni el tabernáculo de un Poder fundante del orden, ni el único o mejor regulador del mercado, ni el depositario de la racionalidad, por tanto, no es el objetivo (positivo) de la política ni el centro hacia el cual debe orientarse la acción de cambios. No representa el núcleo. El Estado es siempre equívoco, instala un simulacro de universalidad, con lo cual dota de legitimación a los intereses particulares que representa" (2000:111). 
debe recuperar de forma nueva el ideal originario de la desestatización. El mejor Estado es aquel desde donde se puede combatir contra el propio Estado, desarrollando la asociatividad de ciudadanos, trabajadores, productores" (111). En palabras de Charles Bettelheim (1970), citadas por Moulian (2000:117)

La lucha por el socialismo requiere del debilitamiento del Estado de la tradición occidental como lugar de localización del poder político. Por ello el socialismo es democracia global, forma deliberativa de vida social y superación de la democracia como régimen representativo.

En Socialismo del siglo XXI. La quinta vía, Moulian (2000), expone los que a su juicio son los tres principales retos que debe enfrentar este tipo de socialismo si en verdad pretende alcanzar sus objetivos: el primero es la creación de una democracia participativa que sustituya a la democracia puramente representativa; el segundo, la instauración de una economía regida por la lógica de las necesidades y de producción de "sujetos económicos", y el tercero, finalmente, la institución de una cultura asociativa fundamentada en la fraternidad. Veamos a continuación algunos detalles de estos desafíos (Moulian, 2000:119-171)

1. Creación de una democracia participativa ${ }^{16}$. Para llegar a construir una democracia plena es necesario ampliar las fronteras de la libertad política, de la representación y de la participación. Cuando esto ocurre, el poder político se fragmenta y se esparce disminuyendo la distancia entre gobernantes y gobernados; es decir, se da una socialización del poder político que debilita el poder absoluto del Estado y lo va convirtiendo en un semi-Estado. La democracia participativa presupone, entonces, la transformación del Estado, no su completa extinción. En efecto: "El nuevo socialismo conserva la vocación anti-estatista promulgada por la mayor parte de los marxistas y se propone buscar activamente que el Estado devenga semi-Estado, sin creer sin embargo que éste pueda extinguirse" (Moulian, 2000:120). Aun así, la democracia participativa requiere de otras condiciones, tales como: iniciativa popular en materia legislativa, democracia interna en los partidos y politización de sus debates, espacio público abierto y plural, funcionamiento de asociaciones autónomas de resguardo de los derechos humanos de tipo político y, por último, reforzamiento de la libertad personal frente a los problemas morales.

2. Instauración de una nueva economía. La economía del nuevo socialismo puede ser definida por los siguientes atributos: a) orientada hacia la satisfacción de las necesidades básicas; es decir, no una economía que le haga el juego al mercado y que se base en la lógica

16. Sobre este tipo de democracia, véase el interesante trabajo de Boaventura De Sousa Santos (2005): Democratizar la democracia. Los caminos de la democracia participativa. En éste se realiza un interesante recorrido dividido en tres grandes secciones: 1aㅡ el análisis de los movimientos sociales en relación con las aspiraciones, 2a) las instituciones y actores políticos que entran en juego y, 3ạ) la democracia participativa en acción. Culmina con un comentario general sobre las "otras" democracias. 
de la ganancia, la acumulación y el despilfarro, sino una economía capaz de satisfacer las necesidades medias de la vida contemporánea y que genere riqueza, pero no para hacer del consumo desaforado una forma de vida, sino para asegurar unas condiciones de vida digna y confortable para toda la población; b) combinación de propiedad privada con propiedad social, o sea, una economía compleja y mixta que armonice un conjunto pequeño de empresas estatales con empresas privadas y con empresas asociativas ${ }^{17}$ para que todos los hombres vivan mejor, puesto que pasan de ser meros "sujetos" a ser "sujetos económicos" (no simples receptores de la actividad económica, sino gestores de la misma); y c) una economía orientada hacia el desarrollo, precisamente, de "sujetos económicos", es decir, personas (productores y consumidores) con capacidad de percibir la racionalidad social de la actividad económica y de participar activamente en los procesos de planificación y decisión que ella demanda ${ }^{18}$. "En la medida que la economía se politiza a través de la participación de los sujetos políticos tiene la posibilidad de hacerse humana y de estar en realidad orientada a la vida"19, concluye Moulian (2000:154).

3. Institución de una cultura asociativa. Esta institución se manifiesta en dos frentes: por un lado, la creación de una cultura del ser, y por otro, la creación de una cultura comunitaria. Ambas culturas buscan generar orientaciones de valor distintas a las existentes en la cultura burguesa: la cultura del ser surge en oposición a la del tener; mientras que la cultura comunitaria nace en contraposición a la individualista. La cultura del ser no implica, como muchos creen, que se tenga que renunciar a los bienes y a las cosas; antes bien, se trata de que el tener esté al servicio del ser y ello se logra cuando el énfasis se pone en el desarrollo de las potencialidades de realización del hombre que lo convierten en sujeto/ persona. Construir una cultura del ser exige generar oportunidades para el desarrollo de la individuación, del entendimiento y de la creatividad. La cultura comunitaria, por su parte, se refiere a producir una manera de ser donde los valores de la fraternidad y la solidaridad entren en competencia contra los valores de la utilidad y el instrumentalismo, propios de la sociedad capitalista.

17. Las empresas asociativas o de carácter solidario deben tener un papel importante y creciente en el sistema económico del socialismo del siglo XXI. "Se pueden distinguir tres tipos de empresas asociativas: las empresas accionarias de nuevo tipo, las empresas cooperativas y las empresas de trabajadores" (Moulian, 2000:149).

18. En este sentido, no se debe olvidar que el objetivo principal del socialismo del siglo XXI es la democratización global de la sociedad. Según Moulian (2000), en el terreno político ese objetivo se debe realizar en la democracia participativa y en el terreno económico en una amplia participación de productores y consumidores en la gestión de la economía en los ámbitos local, regional y nacional.

19. A este respecto recuérdese que, según el fundador de Economía y Humanismo, Louis-Joseph Lebret (1966), la economía debe estar al servicio de la vida y de la humanización de los hombres. Pero para que esto no se quede en simple teoría, el pensador construye la categoría de "arbitraje para una nueva noción de planificación". Según esta categoría, primero hay que construir colectivamente los arbitrajes de las finalidades económicas (que deben girar en torno de la vida y la humanización), y luego planificar centralmente un conjunto de metas y procedimientos obligatorios para realizar los arbitrajes de los medios económicos. 
Al disertar sobre estas mismas temáticas, Heinz Dieterich Steffan, en El Socialismo del siglo $X X I$, se pregunta -en alusión a la polémica suscitada entre Ariel Dorfman y Samir Amín 20_: "¿Tiene razón Samir Amín cuando afirma que el socialismo es la única alternativa real al neoliberalismo?", y responde:

Contestaré mediante la discusión de tres interrogantes: 1. ¿Ha llegado el momento histórico para construir e implementar un nuevo proyecto socialista, es decir, la democracia real participativa? 2. ¿Existe el socialismo ya como Nuevo Proyecto Histórico, no como "retorno al pasado", sino como un cuerpo teórico consistente sobre la civilización del futuro, la que Marx llamaba el reino de la libertad? 3. ¿Fuera del socialismo, existe otra alternativa real al neoliberalismo? (Dieterich, 2006:12).

Al tratar con mayor detalle los interrogantes esbozados, este autor llega a las siguientes conclusiones:

- El momento histórico para construir e implementar el socialismo del siglo XXI ya llegó, puesto que la civilización burguesa en la que se asienta el sistema capitalista está tocando su fin. Esta constatación se basa en los conocimientos científicos y éticos que demuestran que la fase clásica de la burguesía, que se inició al terminar la Segunda Guerra Mundial y que alcanza su configuración más evolucionada marca, al mismo tiempo, su ocaso hacia la civilización postcapitalista. Particularmente hay tres evidencias que así lo hacen ver: 1. El agotamiento estructural de las instituciones básicas del sistema burgués; 2. la aparición de las estructuras constitutivas en el seno de la nueva civilización postburguesa en la sociedad global contemporánea y, 3. la lógica de la evolución social de la humanidad (Dieterich, 2006:2-31).

- Ya existe el socialismo como Nuevo Proyecto Histórico, no como retorno al pasado, sino como un cuerpo teórico consistente sobre la civilización del futuro. Este nuevo proyecto estipula un cambio institucional que se manifiesta en, al menos, cuatro instancias básicas: $1^{\circ}$ ) una economía planificada de equivalencias, $2^{\circ}$ ) una democracia directa, $3^{\circ}$ ) un Estado no-clasista $y, 4^{\circ}$ ) un sujeto racional-ético-estético (Dieterich, 2006:39-50). En la tabla 1 se esquematiza el cambio institucional haciendo un contraste entre la civilización burguesa y la civilización democrática.

20. Esta polémica se suscitó en el Foro de Porto Alegre de enero de 2001, cuando un intelectual prestigioso, Samir Amín, afirmó que "la única salida al caos neoliberal es el socialismo", a lo que al día siguiente el intelectual chileno Ariel Dorfman respondió diciendo que no se puede afirmar que el socialismo es la única opción real frente al neoliberalismo, que tal aseveración es "una ampulosidad grandilocuente" y que plantear el socialismo del tercer milenio como salida al neoliberalismo es "un retorno" al pasado. 
Cuadro 1. Institucionalidad burguesa versus institucionalidad participativa

\begin{tabular}{|c|c|}
\hline $\begin{array}{l}\text { Institucionalidad de la democracia burguesa } \\
\text { (Sociedad global capitalista) }\end{array}$ & $\begin{array}{l}\text { Institucionalidad de la democracia } \\
\text { participativa (Sociedad global postcapitalista) }\end{array}$ \\
\hline $\begin{array}{l}\text { Crematística nacional de mercado } \\
\text { - Crematística }{ }^{21} \text { con planificación de élite } \\
\text { inversionista/capitalista } \\
\text { - Precios subjetivos, determinados por poder. } \\
\text { - Intercambio desigual, explotación-enajenación. }\end{array}$ & $\begin{array}{l}\text { Economía de equivalencias } \\
\text { - Economía con planificación democrática, } \\
\text { micro y macro. } \\
\text { - Valor objetivo, determinado por aportación } \\
\text { laboral. } \\
\text { - Intercambio de equivalencias. }\end{array}$ \\
\hline $\begin{array}{l}\text { Democracia formal } \\
\text { - Democracia de forma: primer nivel de } \\
\text { democracia posible, limitada a esfera política. } \\
\text { - Plutocrática } \\
\text { - No representativa, sino sustitutiva de voluntad } \\
\text { general. }\end{array}$ & $\begin{array}{l}\text { Democracia participativa } \\
\text { - Desarrollo más alto posible de democracia: } \\
\text { abarca las cuatro relaciones sociales humanas: } \\
\text { economía, política, cultura y militar. } \\
\text { - Plebiscitaria electrónica (Internet) en decisiones } \\
\text { trascendentes. } \\
\text { - Recupera democracia formal, agrega } \\
\text { democracia social y participativa (material = de } \\
\text { contenido). }\end{array}$ \\
\hline $\begin{array}{l}\text { Estado clasista } \\
\text { - Función clasista (comité ejecutivo de intereses } \\
\text { comunes de élite económica) determina su } \\
\text { identidad. } \\
\text { - Funciones generales distorsionadas por función } \\
\text { clasista. }\end{array}$ & $\begin{array}{l}\text { Estado no-clasista } \\
\text { - Funciones clasistas desaparecen, con ellas } \\
\text { identidad represiva del Estado. } \\
\text { - Estado se convierte en administración } \\
\text { legitimada de funciones generales. }\end{array}$ \\
\hline $\begin{array}{l}\text { Sujeto crítico-ético-estético } \\
\text { No puede existir en este entorno institucional; lo } \\
\text { sustituye el sujeto liberal posesivo. }\end{array}$ & $\begin{array}{l}\text { Sujeto crítico-ético-estético } \\
\text { En este entorno institucional el ciudadano se } \\
\text { convierte en sujeto pleno de las tres dimensiones } \\
\text { de la condición humana. }\end{array}$ \\
\hline
\end{tabular}

Fuente: Dieterich, 2006, p. 50.

- La única alternativa real al neoliberalismo es el socialismo. En efecto, "La destrucción económica y social de medio siglo de recolonización neoliberal en América Latina ha convertido sus economías en sistemas inviables para la tarea que deberían cumplir: satisfacer las necesidades básicas de la población" (Dieterich, 2006, p.66). ¿Cómo salir, entonces, de este panorama de inviabilidad estructural? Políticamente existen cuatro vías posibles para América Latina: $1^{\circ}$ ) el proyecto de centro derecha o neoliberalismo, $2^{\circ}$ ) el

21. La crematística se refiere a la economía de mercado, o lo que es lo mismo, un modelo económico fundamentado en el lucro (nota del autor). 
proyecto de centroizquierda, $3^{\circ}$ ) la guerrilla clásica, y $4^{\circ}$ ) el proyecto bolivariano. De estas opciones, sólo la cuarta es válida dado que propone un bloque regional de poder (Patria Grande) que supera los límites nacionales al plantear la implementación de un mercado y un Estado regional que pueda defender ante Estados Unidos y la Unión Europea el bloque proteccionista latinoamericano. Además, para entender las vías de desarrollo posible que pueden tomar las naciones latinoamericanas en el emergente sistema mundial multipolar hay que comprender las cinco grandes tendencias o fuerzas evolutivas que determinan la sociedad global en su época moderna; ellas son: $1^{\circ}$ ) ley de la gravitación política, $2^{\circ}$ ) liberalismo, neoliberalismo, libre comercio, $3^{\circ}$ ) capitalismo proteccionista de Estado, $4^{\circ}$ ) Bloque Regional de Poder fincado en el capitalismo de Estado proteccionista, $5^{\circ}$ ) democracia participativa. Esta última tendencia es la mejor salida para América Latina debido a que representa el advenimiento de la sociedad postcapitalista y, por tanto, la civilización del futuro. Pero para llegar a esta meta el programa de transformación nacionalregional (de las tendencias 3 y 4) debe integrar, desde su inicio, demandas y elementos de la democracia participativa (Dieterich, 2006:66-73).

Por lo dicho hasta aquí, parece haber consenso entre los intelectuales sobre el progresivo agotamiento del capitalismo. Este es un hecho que el mismo Schumpeter -considerado por algunos como "el Marx de la burguesía"- había vaticinado en 1942 en su libro Capitalismo, socialismo y democracia, obra en cuya tesis principal sostiene que, inevitablemente, el socialismo reemplazará al capitalismo. Y no, como creía Marx, debido a las fallas del capitalismo sino justamente por sus éxitos: el progreso y las innovaciones se volverán rutina y, entonces, el capitalismo deberá cederle el sitio a un sistema más racional. El capitalismo es capaz de generar intensos procesos de "creación destructiva". En este contexto, Schumpeter se pregunta si la democracia y el socialismo son compatibles, lo cual lo remite a la cuestión previa de saber qué es la democracia. Responde que la democracia debe entenderse como un método político y no como un fin en sí misma. De ahí que cualquier afirmación acerca de su funcionamiento carezca de sentido sin una referencia a tiempos, lugares y situaciones dados. La democracia puede o no contribuir al desarrollo económico, a la justicia social o a que todos coman, sean más sanos y se eduquen: el hecho fundamental es que se trata exclusivamente de un procedimiento (Nun, 2000). ¿Es el socialismo el mejor escenario para el florecimiento de democracias auténticas? La respuesta de Rosa Luxemburgo (1978), es tajante: "No hay democracia sin socialismo, ni socialismo sin democracia".

Ahora bien, lo cierto es que, en América Latina, el florecimiento de diversos movimientos y tendencias (nuevas fuerzas políticas y sociales) demuestra que el socialismo del siglo XXI es el camino más cierto y seguro -como se ha expuesto hasta aquí-. Así lo deja ver Atilio Borón (2005) al referirse a las "promesas y desafíos de la izquierda latinoamericana a comienzos del siglo XXI". En este trabajo Borón demuestra que a partir de los años noventa del siglo XX, en esta región se ha dado un lento, pero progresivo agotamiento del neoliberalismo, que ha llevado al surgimiento de nuevas expresiones de la política de izquierda, que a su vez, dan cuenta del 
fracaso de los capitalismos democráticos ${ }^{22}$. Además, las democracias latinoamericanas se han presentado como democracias vacías de contenido y, dadas sus reiteradas frustraciones, han alentado fenómenos tales como: el surgimiento de fuerzas sociales contradictorias, la explosión de múltiples identidades (étnicas, lingüísticas, de género, sexuales, etcétera) y, en últimas, la globalización de las luchas contra el neoliberalismo. Ante este panorama los desafíos históricos de quienes se oponen al neoliberalismo rampante a comienzos del siglo XXI en América Latina, son descomunales: Por un lado deben "construir partidos, movimientos y organizaciones genuinamente democráticos como una forma de prefigurar la naturaleza de su futuro Estado"; por otro lado "neutralizar el accionar de los aparatos ideológicos de la burguesía y hacer llegar su mensaje y su discurso al conjunto de la población, que por cierto no tiene sus oídos preparados para escuchar un mensaje socialista" (Borón, 2005:429).

Por último, Marta Harnecker (2010), propone unas tareas o medidas concretas que "desde el Estado heredado habitado por cuadros revolucionarios" se pueden ir adoptando para avanzar hacia la construcción del socialismo del siglo XXI. Estas tareas constituyen un gran desafío y se pueden llevar a feliz término siempre y cuando se cuente con voluntad política. Son las siguientes: 1) avanzar en una nueva integración de la región, 2) conquistar espacios que hasta ahora han estado bajo el dominio del capital, 3) aplicar estrategias que posibiliten el cambio de las relaciones de producción (transformación de las empresas estatales y de las empresas capitalistas y creación y fortalecimiento de las cooperativas), 4) cambiar las reglas del juego institucional, 5) crear nuevas instituciones, 6) transformar las instituciones heredadas, 7) impulsar la construcción del nuevo Estado desde abajo, y 8) diseñar una guía para evaluar el avance del proceso.

\section{CONCLUSIONES}

No cabe duda de que nuestra América ha sido el escenario de múltiples y complejos procesos sociales que, históricamente, la han sumido en la explotación, el abandono y la dependencia. El subdesarrollo que la ha caracterizado no es fruto del azar; por el contrario, es el resultado de un sistema conscientemente ideado y ejecutado por élites y centros de poder que han buscado siempre defender e imponer sus propios intereses políticos, económicos, sociales y culturales a expensas del bienestar de la inmensa mayoría. La burguesía que la ha dominado ha hecho prevalecer sus mecanismos de alienación y de control por décadas, pero en los últimos años se han presentado acontecimientos y circunstancias que muestran claramente que el capitalismo, y más concretamente el neoliberalismo, es un sistema insostenible y en decadencia que debe darle paso a una nueva realidad: el socialismo del siglo XXI.

22. En América Latina estos capitalismos fracasaron porque "la democracia trajo bajo el brazo políticas de ajuste y estabilización, precarización laboral, altas tasas de desocupación, aumento vertiginoso de la pobreza, vulnerabilidad externa, endeudamiento desenfrenado y extranjerización de nuestras economías (Borón, 2005:411). 
Indudablemente, hablar de socialismo hoy tiene sentido, y más en América Latina donde, como ya se ha afirmado, el capitalismo salvaje (por lo general aplicado a ultranza) ha sido nefasto y ha acumulado injusticia, exclusión, pobreza, desempleo, inequidad, depredación de los recursos naturales y todos los antivalores y contradicciones que es capaz de generar, reproducir y distribuir. En efecto, si bien es cierto que este sistema en la actualidad ha alcanzado su pleno desarrollo y tiene dimensiones mundiales, la verdad es que su esencia sigue siendo la de siempre: el afán desmedido de riqueza que lo convierte todo en mercancía, inclusive a la naturaleza, al trabajo y a las personas.

Por otra parte, la expresión "socialismo del siglo XXI" hace alusión a la combinación del socialismo con la democracia participativa y directa. Es una tendencia que busca dar respuestas al grave problema de subdesarrollo en que vive sumida América Latina debido, como ya se indicó, a los estragos del capitalismo. El socialismo del siglo XXI es una manifestación actual del socialismo; es decir, del periodo de transición, relativamente prolongado, del capitalismo al comunismo. Por eso, este "nuevo socialismo" parte de las pre-comprensiones socialistas que se hallan en los fundadores del marxismo.

El socialismo del siglo XXI presupone un trasfondo democrático: es necesario construir en la región y en cada uno de sus países una democracia participativa o directa que deje atrás a la tradicional democracia representativa. El punto de partida debe ser la dignidad inviolable de todo ser humano, lo cual exige: considerar al hombre como un ser eminentemente social, apuntarle al pleno desarrollo humano, instituir una democracia participativa, crear un nuevo modelo económico, y alcanzar un alto grado de descentralización.

La meta que persigue el socialismo es el pleno desarrollo humano, no el desarrollo por el desarrollo, la economía por la economía o la política por la política; todas estas realidades cobran sentido cuando se las mira a la luz de la persona humana y su circunstancia históricosocial concreta. Ello es universalmente válido, pero se hace más evidente si se habla de América Latina, pues como se sabe, el desarrollo se hace más necesario y más sentido precisamente ahí donde ha brillado por su ausencia. En efecto, una gran parte de este territorio se debate entre el subdesarrollo, la pobreza y la dependencia. El pleno desarrollo humano precisa definir un horizonte socialista fincado en tres grandes aspectos: unos valores y principios modulares, un programa del proyecto y un sujeto histórico.

Este trabajo demuestra que el "nuevo socialismo" para el siglo XXI es la vía a través de la cual América Latina puede cambiar la historia y construir un mejor futuro. Sin embargo debe enfrentar numerosos y complejos desafíos. El primero de ellos está asociado a la necesaria "transformación" del Estado. Pero existen otros igualmente importantes tales como: la construcción de partidos, movimientos y organizaciones genuinamente democráticos; la nueva integración de la región; la conquista de espacios que tradicionalmente han estado bajo el dominio del capital; la aplicación de estrategias que posibiliten el cambio de las relaciones de producción; el cambio de las reglas del juego institucional; la creación de nuevas instituciones, etcétera. 


\section{REFERENCIAS}

- Ancada, J.L. (2008). "Transición", en: Cuadernos de Pensamiento Crítico RUTH №1, pp.40-60. Panamá: RUTH, Casa Editorial.

- Bettelheim, C. (1970). La transition vers I’economie sociliste. Paris: ed. Francois Maspero.

- Borón, A. (2000). Tras el búho de Minerva. Mercado contra democracia en el capitalismo de fin de siglo. Buenos Aires: CLACSO.

- Borón, A. (2005). "La izquierda latinoamericana a comienzos del siglo XXI: promesas y desafíos", en: César Rodríguez, Patrick Barrett y Daniel Chávez (Editores). La nueva izquierda en América Latina. Sus orígenes y su trayectoria futura. Bogotá: Norma. pp. 405-433.

- Borón, A. (2008). Socialismo del siglo XXI ¿Hay vida después del neoliberalismo? Buenos Aires: Ediciones Luxemburg.

- De Sousa Santos, B. (2005). Democratizar la democracia. Los caminos de la democracia participativa. México: Fondo de Cultura Económica.

- Díaz Salazar, R. (s.f.). "Foro de Porto Alegre: movimientos por la justicia global", recuperado el 1 de marzo de 2013, de: http://www.foro-ellacuria.org/publicaciones/Informe7Salazar. html

- Dieterich S. H. (2006). El Socialismo del siglo XXI. Berlín: Gegenstandpunkt (Versión en español disponible en: http://libertatsolidaria.pangea.org/El_Socialismo_del_Siglo_ XXI.pdf)

- Eagleton, T. (2006). "¿Un futuro para el socialismo?", en: Atilio Borón, Javier Amado y Sabrina González (Compiladores), La teoría marxista hoy. Problemas y perspectivas. Buenos Aires: CLACSO.

- Engels, F. (1965). Anti-Dühring. La Habana: Editora Política.

- Fernández L. C. y Alegre Zahonero, L. (2006). Comprender Venezuela, pensar la democracia. El colapso moral de los intelectuales occidentales. Caracas, Venezuela: Fundación Editorial el perro y la rana.

- Fernández L. C. y Alegre Zahonero, L. (2008). "El socialismo del siglo XXI", en: Cuadernos de Pensamiento Crítico RUTH Nº1, pp.88-107. Panamá: RUTH, Casa Editorial. 
- Guanche, J. C. (2008). "Todo lo que existe merece perecer (o una pregunta distinta sobre la democracia)", en: Cuadernos de Pensamiento Crítico RUTH Nº1, pp.201-243. Panamá: RUTH, Casa Editorial.

- Gunder Frank, A. (1970). Capitalismo y subdesarrollo en América Latina. La Habana: Editorial de Ciencias Sociales.

- Hamburger, Á. (2010). Humanización de la empresa. Hacia una ética aplicada en las organizaciones. Bogotá: Universidad de San Buenaventura.

- Harnecker, M. (2010). América Latina y el socialismo del siglo XXI. Guatemala: Secretaría de la Paz.

- Harnecker, M. (2011). "Democracia y socialismo: el futuro enraizado en el presente", en: Estudios críticos del desarrollo, Vol. I, Núm. 1, pp.151-182.

- Hinkelammert, F. (1998). El Mapa del Emperador. San José de Costa Rica: Ediciones del DEI (Departamento Ecuménico de Investigaciones).

- Houtart, F. (2007). Un socialismo para el siglo XXI. Cuadro sintético de reflexión. Ponencia presentada en las Jornadas "El socialismo del siglo XXI", Caracas, junio.

- Lebowitz, M. (2006). Construyámoslo ahora. El socialismo para el siglo XXI. Caracas: Centro Internacional Miranda.

- Lebowitz, M. (2008). El camino del desarrollo humano ¿Capitalismo o Socialismo?. Caracas: Centro Internacional Miranda.

- Lebret, L.-J. (1966). Dinámica concreta del desarrollo. Barcelona: Herder.

- Lenin, V. (1961). "El Estado y la revolución", en: Obras escogidas, t. II (3 t.). Moscú: Editorial Progreso.

- Löwy, M. (2011). Ecosocialismo. La alternativa radical a la catástrofe ecológica capitalista. Buenos Aires: Herramienta.

- Luxemburgo, R. (1978). “'Reforma o revolución?”, en: Rosa Luxemburgo. Obras escogidas. Madrid: Fundación Rosa Luxemburgo.

- Mariátegui, J. C. (1969). "Mensaje al Congreso Obrero", en: Ideología y Política. Lina: Amauta. 
- Martínez Heredia, F. (2008). "Socialismo", en: Cuadernos de Pensamiento Crítico RUTH Nº1, pp.13-39. Panamá: RUTH, Casa Editorial.

- Marx, C. y Engels, F. (1974). "Crítica al Programa de Gotha", en: Obras escogidas, t. III (3 t.). Moscú: Editorial Progreso.

- Marx, C. y Engels, F. Federico (1979a). Manifiesto del Partido Comunista. Moscú: Editorial Progreso.

- Marx, C. y Engels, F. (1979b). La ideología alemana. La Habana: Editorial Política.

- Monedero, Juan Carlos (2010). "Las democracias en América Latina: la reinvención postneoliberal dela política", en: Comuna, Revista del Centro Internacional Miranda (Caracas) Año 2, №2, enero-marzo, pp.215-2445.

- Moulian, T. (2000). El socialismo del siglo XXI. La quinta vía. Santiago de Chile: LOM Ediciones.

- Nun, J. (2000). Democracia igobierno del pueblo o gobierno de los políticos? Buenos Aires: Fondo de Cultura Económica.

- Zecevic, M. (1977). "El sistema de delegados", en: Marta Harnecker (trad. y selec. de textos) (2007). El sistema político yugoslavo: buscando un camino alternativo al sistema representativo burgués y al sistema estatista soviético. Caracas: Centro Internacional Miranda. 